\title{
Antecedents of Psychological Adjustment of International Students Studying in China: The Roles of Self-Efficacy and Self-Esteem
}

\author{
Werede Tareke Gebregergis*, Desbele Tekie, Dawit Yikealo, Aster Habte \\ Central China Normal University, Wuhan, China \\ Email: *weredetarekeg@yahoo.com
}

How to cite this paper: Gebregergis, W.T., Tekie, D., Yikealo, D. and Habte, A. (2019) Antecedents of Psychological Adjustment of International Students Studying in China: The Roles of Self-Efficacy and Self-Esteem. Open Journal of Social Sciences, 7, 233-254. https://doi.org/10.4236/jss.2019.72019

Received: December 20, 2018

Accepted: February 25, 2019

Published: February 28, 2019

Copyright $\odot 2019$ by author(s) and Scientific Research Publishing Inc. This work is licensed under the Creative Commons Attribution International License (CC BY 4.0).

http://creativecommons.org/licenses/by/4.0/

\begin{abstract}
Among many factors, individual difference variables are believed to be critical aspects of students' psychological adjustment. The present study was, therefore, conducted in this context to determine the relationships between self-efficacy, self-esteem and psychological adjustment variables of depression and life satisfaction. The participants of the study were international university students $(N=328)$ studying in three Chinese universities in Hubei Province, Wuhan. To obtain the data, self-report questionnaires were distributed among the participants measuring their levels of self-efficacy, self-esteem, life satisfaction and depression. Hierarchical multiple regression analyses were performed to explore the relationship between the study variables while controlling the demographics. The regression output showed that both self-efficacy and self-esteem were positively related to life satisfaction and negatively related to depression. The study further conducted mediation analyses with the help of regression PROCESS macro. The mediation results indicated that self-esteem and life satisfaction showed full parallel mediating effects on the relationship between self-efficacy and depression. Self-esteem also mediated the self-efficacy-depression relationship. Exploring the relationships between the study variables may enrich the scientific understanding of acculturative psychological outcomes in the context of individual difference variables. Findings may also provide direction for host university communities in nurturing the self-esteem and self-efficacy of their fellow international students to better deal with their psychological adjustment difficulties.
\end{abstract}

\section{Keywords}

Self-Efficacy, Self-Esteem, Psychological Adjustment, International Students 


\section{Introduction}

Globalization, one of the most prominent features of the $21^{\text {st }}$ century, has rapidly been maintaining a global ground for social, cultural, economic, and political integrity [1]. In the global community, globalization appears to impact every aspect of human change and growth. It is the foundation of the knowledge-based global economy. As part of the global integrity, internationalization of higher education has been undergoing rapid changes, which has accelerated the mobility of international students around the globe. According to UNESCO, 2014 (cited in [2]), the global number of international students studying outside their home has got to be more than doubled since 2000 to approximately four million in the year 2012; and the number is expected to climb to 15 million in the year 2025 [3]. The international higher education market has been dominated by English speaking counties, like North America, Australia and UK [3] [4]. However, due to China's remarkable achievement in the realm of science and technology and the popularity of the Chinese language across the world, Chinese higher education internationalization has been recently swiftly growing, making the country to be one of the top study destinations in the world, attracting a considerable number of international students [5] [6]. According to data from the Ministry of Education (MOE) of the People's Republic of China, there were more than 489,200 international students in the country in the year 2017 [7].

Internationalization of education provides a wide range of mutual benefits to both international students and the host countries. Academic growth, open-mindedness, multicultural mentality, and future career opportunities are some of the benefits for international students. On the other hand, the full range of multidisciplinary skills and knowledge of the students significantly enhances the intellectual capital and workforce, and thereby the knowledge-based economic development of the host country [8]. Nevertheless, the internationalization of education is thought to place a wide range of adjustment difficulties on sojourn students. As international students, we have personally experienced that moving to a new educational, social, cultural and ecological environment is inherently stressful and overwhelming especially at the arrival time and the first few months.

Many scholars in the field of acculturation have consistently reported that international students undergo a broad range of psychological and sociocultural adjustment difficulties which might put the students at the risk of developing severe mental health problems [9] [10] [11]. More specifically, the common challenges that international students encounter include language barriers, perceived discrimination, financial concerns, homesickness, academic pressure and culture shock [12] [13] [14]. Similarly, several studies conducted among international students studying in China revealed that the students experienced mental health problems, such as stress and depression as a result of acculturative stressors [15] [16] [17]. In light of the psychological adjustment difficulties and their devastating impact on psychological well-being, numerous researchers have at- 
tempted to figure out factors that facilitate positive acculturative outcome of the students. Among the factors, cultural and emotional intelligence, coping strategies, personality, spiritual and social support, self-efficacy and self-esteem were found to contribute positively to the psychological adjustment of the students [13] [18].

\subsection{Literature Review}

\subsubsection{Psychological Adjustment}

According to Searle and Ward [19], cross-cultural adjustment can be meaningfully conceptualized in two distinct yet intertwined domains: psychological (emotional/affective) and sociocultural (behavioral). Psychological adjustment refers to the overall psychological, emotional and affective state of wellbeing and life satisfaction. Psychological adjustment includes a range of changes related to: beliefs, perceptions, values, ideologies, and attitudes while behavioral adjustment includes: dressing, eating, talking, social interaction patterns, and language skills that the acculturative person depicts during the process of acculturation [20].

On the other hand, sociocultural adjustment was conceptualized as how an acculturating individual learns and develops multicultural competencies necessary for effective functioning and living in the host environment [20]. The two forms of adaption do not, however, function independently. Instead, they are closely related to one another [20] [21]. As both psychological and sociocultural forms of adjustment are problem-oriented, positive sociocultural interaction uplifts psychological wellbeing and psychological health status enhances an individual's learning development of intercultural interactions and communication skills [21]. Although the two domains of cultural transitions are interrelated, their theoretical foundations are different. Sociocultural adjustment is best conceptualized and elucidated within the cultural learning theory of acculturation whereas psychological adjustment is best explained and understood within the stress and coping model [20]. Thus, the present study is grounded in the psychological stress and coping approach assuming that both self-esteem and self-efficacy are part of individual coping resources which can be employed to deal with psychological adjustment difficulties.

According to the psychological model of stress and coping, the cultural transition is a continuous life experience that brings stress and tension to individuals based on their resources and copings [22]. For instance, under the umbrella of Lazarus and Folkman [23] stress, appraisal, and coping framework, Berry [24] developed an acculturation stress model which states that when individuals come into first-hand cross-cultural contact, they undergo a significant and exciting new cultural experience. At the same time, such experiences might be interpreted as threatening, demanding, challenging and perplexing which individuals may hardly effectively cope with, especially at the beginning stage of the transition. Therefore, when individuals fail to effectively cope with acculturative difficulties because of their negative appraisal, they may be at a higher risk of developing acculturative stress which may detrimentally affect the quality of their psychological acculturation outcomes such as physical and mental health 
[9] [10] [25].

The emphasis of stress and coping approach is, therefore, on the accelerating role of personal attributes and strategies in adjustment to the new cultural setting. Consequently, this emphasis has inspired the attention of many cross-cultural researchers to identify the psychological factors that speed up positive adjustment outcomes of the students and thereby shield them from experiencing adverse adjustment outcomes such as depression. Personal resources such as self-resilience [26], emotional intelligence and intelligence [13] [27], personality traits and copings [18], are believed to contribute to students' adaptation process. As part of these endeavors, several cross-cultural researchers have argued that self-efficacy [28] and self-esteem are critical features of individuals' adjustment outcomes.

\subsubsection{Self-Efficacy and Psychological Adjustment}

Self-efficacy is defined as "people's beliefs about their capabilities to exercise control over events that affect their lives" ([29], p. 1175). It also involves individuals' beliefs in their competencies to mobilize the passions, motivations, cognitive resources, and courses of action needed to accomplish a particular set of task demands [30] [31]. The social cognitive theory of Bandura [31] postulates that the perceived level of self-efficacy powerfully impacts the change-producing behaviors of an individual in a particular domain through four processes: cognitive, affective, motivational and selection. Following Bandura's theory, several cross-cultural studies have echoed the critical role self-efficacy in intercultural adjustment. For instance, Harrison, Chadwick [32] found high self-efficacious individuals to have better intercultural interactions, work and general adjustment than low self-efficacious individuals.

Similarly, drawing on the social cognitive theory, Li and Gasser [33] assumed that sojourners with a high level of self-efficacy have the capability of visualizing positive adjustment outcomes during the cultural contact and transition and subsequently experience less mental health problems such as stress, depression, and anxiety. Besides, highly self-efficacious individuals may actively engage and mobilize their full attention, drive, and passion towards the success of the intercultural adjustment. Further, Li and Gasser [33] mentioned that people with high self-efficacy might opt to participate in intercultural interaction with the mainstream society notwithstanding cross-cultural interaction demands sufficient cultural information, acceptance and open-mindedness.

The positive contribution of self-efficacy in the adjustment of international students was also empirically substantiated by some studies, although the studies are inadequate [18]. For instance, Hechanova-Alampay, Beehr [28] have carried out a longitudinal study among 294 domestic and international sojourners in the US and found self-efficacy, social support, and cultural novelty to have a predicting effect on students' adjustment and strain at different cultural transition stages. In another study, Bulgan and Çiftçi [34] examined the role of marital satisfaction and academic self-efficacy on psychological adaptation (psychological 
well-being and satisfaction). Their findings revealed that marital satisfaction and academic self-efficacy explained $45.9 \%$ of the variance in psychological well-being and $25.8 \%$ in life satisfaction. Also, [35] explored the relations between general self-efficacy, social support and psychological adjustment with the sample of 189 international students in Malaysia and reported that self-efficacy and one dimension of social support were related to psychological adjustment. Several other studies have pointed out that the high level of academic self-efficacy is associated with minimal psychological acculturative difficulties and better psychological health [36]. On the other hand, lower self-efficacy is associated with higher stress, depression, and poor psychological well-being [37] [38].

Although documented literature seems to advocate for the positive impact of self-efficacy on psychological adaptation, some studies questioned whether self-efficacy buffers individuals from mental health problems. For example, in a study conducted by Constantine, Okazaki [39], social self-efficacy and self-concealment failed to significantly mediate the relationship between international students' acculturative stress and their depressive symptoms. Such controversies indicate that the relationship between individual difference factors such as self-efficacy and psychological adaptation still needs further empirical evidence.

\subsubsection{Self-Esteem and Psychological Adjustment}

Self-esteem, which refers to peoples' negative or positive evaluation of themselves, [40] is also one of the psychological factors believed to influence psychological adaptation [41]. Self-esteem is the evaluative aspect of self-concept which represents the nature of people's attitude towards themselves and their competence. According to Kernis [42], self-esteem is thought to be a relatively enduring personal characteristic that incorporates both motivational and cognitive aspects. Generally, people want to be esteemed and are motivated to engage themselves in different activities to achieve a sense of self-worth and competence. Individuals with a high level of self-esteem tend to put a continuous effort to enhance their feeling of self-worth [43]. On the other hand, individuals with a low level of self-esteem focus on protecting their self-worth [44]. Therefore, self-esteem is a critical feature of psychological functioning and is strongly associated with people's sense of general satisfaction (Tayler and Brown, 1988 as cited in [41]).

According to Pearlin et al. (1981) as cited in [41], self-esteem is a personal stress coping resource that empowers people to deal with stressful situations. Similarly, Anderson [45] stated that people's feeling of self-worthiness and respect could be shown as an ability to deal with stress. It was also suggested that people's self-esteem, interpersonal confidence, and coping capabilities are associated with psychological problems such as anxiety, depression, anger and withdrawal in stressful circumstances [46]. In this sense, self-esteem seems to function in the same way in people's psychological adjustment. Research studies on this regard suggest that positive self-evaluation accelerates healthy interper- 
sonal relationships in a way that people are more engaged in and contribute much to their relationships when they are confident and have a sense of self-respect but less involved and contribute less when they have low self-esteem [47] [48].

Several cross-cultural studies have also explored that self-esteem contributes to positive psychological acculturative outcomes. For instance, Kim, Hogge [49] conducted a study among immigrants and explored that a high level of self-esteem reduced the debilitating effect of stress on psychological well-being. Similarly, numerous researchers demonstrated that self-esteem was negatively related to loneliness and depression but positively related to happiness [50] [51] and satisfaction with life [52].

\subsubsection{Self-Efficacy, Self-Esteem, and Psychological Adjustment}

Despite self-efficacy and self-esteem are separate constructs [31] [53], previous studies documented a positive association between the two [53] [54]. Highly self-efficacious people accomplish a particular task, and subsequently, their positive self-evaluation may be increased. In this context, self-efficacy seems to predict self-esteem, but self-esteem does not predict self-efficacy [54]. Therefore, from this perspective, it can be assumed that self-esteem can act as a mediator between self-efficacy and psychological adjustment outcomes such as depression and satisfaction with life. Some empirical studies have also provided evidence for the mediating effect of self-esteem. For instance, Hermann [55] explored the relationship between self-efficacy, personality and psychological adjustment outcomes with a sample of 696 college students and reported that self-esteem mediated the social self-efficacy-depression relationship. This finding reflects that a high level of self-efficacy boosts students' self-esteem and thereby reduces the level of depression.

Liu, Wang [56], in their survey study among 412 undergraduate students, have also found that self-esteem mediated the relationship of resilience with both satisfaction and psychological distress, which suggests that resilient students have high self-esteem and, in turn, are satisfied with their lives and experience a low level of psychological distress. Similarly, Capri, Ozkendir [57] explored a correlational relationship between self-efficacy, life satisfaction, and burnout. Another cross-sectional study has also reported that self-efficacy and life satisfaction were positively related to adaptation and negatively related to depression, suggesting that people's higher levels of self-efficacy and life satisfaction were associated with higher adaption and fewer depressive symptoms [58]. Although these studies did not further analyze the intermediary role of life satisfaction, the significant relationships between the variables hint the possibility of mediation effect.

Sketching on the reviewed literature, there is no doubt that international students go through a wide range of intercultural adjustment difficulties which may negatively affect their psychological well-being. With this in mind, researchers noted that individual coping resources such as personality, emotional and cul- 
tural intelligence, and social support could be invested to better deal with the inherently stressful cross-cultural transition [59]. However, empirical studies on the contribution of individual difference factors such as self-efficacy and self-esteem on psychological adaption as well as the mediating effects of self-esteem and life satisfaction on the relationship between predictors and adjustment outcomes are significantly limited [18]. Similarly, there are no sufficient empirical studies on international students' adjustment issues in China albeit the body of the student population in the country is rapidly growing [6]. Given this, the present study has made an effort to discover the relationships between self-efficacy, self-esteem and psychological adjustment variables (i.e., depression and satisfaction with life). Exploring the relationships between the study variables may enrich our scientific understanding of acculturative psychological outcomes and their relation to individual difference variables. Additionally, the current study might guide host university communities on how to better invest in fostering positive psychological adjustment outcomes of their fellow students.

\subsection{Research Hypotheses}

Drawing on the reviewed literature and theoretical conceptualization of the study variables, the study pronounced following guiding hypotheses.

Hypothesis 1. Students with high levels of self-efficacy have better psychological adjustment (lower depression and higher life satisfaction).

Hypothesis 2. Students with high levels of self-esteem have better psychological adjustment (lower depression and higher life satisfaction).

Hypothesis 3. Students' self-esteem and life satisfaction mediate the relationship between their self-efficacy and depression.

Hypothesis 4. Students' self-esteem mediates the relationship between their self-efficacy and life satisfaction.

\section{Methods}

\subsection{Research Design}

This study was a descriptive cross-sectional study in which all study variables were measured at a particular point in time.

\subsection{Participants}

The participants of the study were 328 international students who were selected using a convenient sampling technique from three universities located in $\mathrm{Wu}$ han, Republic of China. The enrollment of the participants for the study was open to international students studying in the specified universities. Optimal sample size with the desired margin of error of $10 \%$ was determined using the formula given as $\mathrm{n}=\mathrm{N} / 1+\mathrm{Ne}^{2}$, where $\mathrm{N}$ is the total number of international students, $\mathrm{n}$ is the desired sample size, and $\mathrm{e}$ is a margin of error. The participants originated from 110 countries; and the majority of them were from Africa (141/43\%) and Asia (133/41\%) and some from Europe (36/11\%) and a few from 
Oceania, South and North America (18/5\%). There were 69 (21\%) married and 128 (39\%) unmarried participants in the study. The participants' average length of stay in China was 18.85 months. Concerning gender, there were 200 (61\%) males and $128(39 \%)$ females, with a mean age of $26.77(S D=5.94)$. The study comprised participants from all educational qualifications of Bachelor (106/32\%), Master (141/43\%) and Doctorate (81/25\%). Regarding the previous travel experience, $200(61 \%)$ of the respondents had previous travel exposure and 128 (39\%) had no prior travel experience before coming to China.

\subsection{Measures}

\subsubsection{Sociodemographics}

To gather the personal information of the participants, some sociodemographic questions about gender, age, marital status, educational level, length of stay and prior travel experience were set as part of the major scales of the study variables.

\subsubsection{Self-Efficacy}

The study employed Schwarzer and Jerusalem [60]'s General Self-efficacy Scale to assess the participants' beliefs in their own capabilities to deal with intercultural difficulties successfully. It is a unidimensional self-report research apparatus with 10 items on four Likert type scale, ranging from 1 (not at all true) to 4 (exactly true). The summed scores range from 10 to 40. High scores represent higher self-efficacy. The reliability of the measure was established by several studies across countries and was found to be high, ranging from 0.70 to 0.90 [54]. Besides, the scale was found to maintain a good criterion validity [54]. The internal consistency of the measure in the present study was 0.82 .

\subsubsection{Self-Esteem}

Rosenberg Self-Esteem Scale, developed by Rosenberg [61], was applied to measure self-esteem. It is a unidimensional, widely used self-report instrument devised to assess individuals" global feeling of self-worth or self-acceptance. The measure comprises 10 items on four Likert scales with the range of 1 (Strongly disagree) to 4 (strongly agree). The sums of the scores range from 10 to 40 with higher scores indicating a high level of self-esteem. The scale is a valid and reliable instrument, and its internal consistency ranges from 0.77 to 0.88 [61]. Besides, the measure was also validated to have good criterion and construct validly [61]. The reliability coefficient of the instrument, as measured using Cronbach's alpha, was high in the present study as well $(\alpha=0.80)$.

\subsubsection{Psychological Adaptation}

Depression and satisfaction with life were used as indices of psychological adjustment.

Depression. Depression was assessed using the Center for Epidemiologic Studies Short Depression Scale (CES-D 10). It is an extensively used self-report measure for depressive symptomatology with 10 items rated on four Likert scales ranging from 1 (rarely or none of the time) to 4 (all of the time). Total scores 
range from 10 to 40 where higher scores indicate greater depressive symptoms. CES-D was found to be a reliable and valid measure of depression across cultures [62]. The alpha value of the measure in the current study was also satisfactory $(\alpha=0.75)$.

Life satisfaction. Satisfaction With Life Scale (SWLS) authored by Diener, Emmons [63] was applied to evaluate participants' general satisfaction with life. SWLS is a short 5-item self-report Likert type of scale ranging from 1 (Strongly disagree) to (Strongly agree). The sum of scores range between 5 and 35 with higher scores indicate higher satisfaction level. Previous studies have asserted that the measure is valid and reliable [64]. The reliable nature of the tool was also evident in the present study ( $\alpha=0.76$ ).

\subsection{Procedure}

The data for the present study were collected in October 2018. Before directly proceeding to data collection, participants were first explicitly informed about the purpose of the study. They were also assured that the data would be kept confidential. Then, upon their agreement to take part in the study, the participants completed a set of questionnaires for self-efficacy, self-esteem and psychological adjustment (depression and satisfaction with life) in their respective classrooms and dormitories.

\subsection{Data Analyses}

First, descriptive statistics such as mean and standard deviation were used to summarize the data. Then, the Pearson product-moment correlation was performed to explore the bivariate relationship between the study variables. Finally, hierarchical multiple regression equations were developed to determine the potential predicting effect of the predictors on the outcome variables. A further regression analyses using PROCESS macro was conducted to test the mediation effects of the presumed mediators.

\section{Results}

\subsection{Descriptive Statistics of Study Variables}

Table 1 presented the summary of mean, standard deviation, skewness, kurtosis and reliability coefficient values of the study variables. Cronbach's alpha was used to determine the internal consistency of the study measures and all the variables

Table 1. Descriptive statistics of the study variables.

\begin{tabular}{ccccccc}
\hline Variables & $M$ & $S D$ & Items & alpha & $S k$ & $K u$ \\
\hline Self-Efficay & 31.94 & 4.44 & 10 & 0.82 & -0.64 & 1.41 \\
Self-Esteem & 31.03 & 5.35 & 10 & 0.80 & -0.36 & -0.30 \\
Depression & 19.38 & 5.05 & 10 & 0.75 & 0.33 & -0.60 \\
Satisfaction With Life & 25.10 & 5.39 & 5 & 0.76 & -0.40 & -0.18 \\
\hline
\end{tabular}


were found to have higher reliability coefficients which were greater than the threshold value of 0.70 [65]. To check the assumption of normality, skewness and kurtoses were computed. According to Gravetter and Wallnau [66], the acceptable limit for the skewness and kurtosis ranges between -2 and +2 . The values of skewness and kurtosis of the present sample data appeared to fit into the acceptable range, indicating that there was no violation of normality.

\subsection{Bivariate Relationships between the Study Variables}

Pearson's product-moment correlation was performed to explore the bivariate relationship between the study variables. Pearson's correlation results (see Table 2 ) indicated that self-efficacy showed a significant negative relationship with depression $(r=-0.29, \mathrm{p}<0.01)$, strong positive relationship with self-esteem $(r=$ $0.43, \mathrm{p}<0.01)$ and life satisfaction $(r=0.43, \mathrm{p}<0.01)$. Likewise, self-esteem was found to have a strong negative association with depression $(r=-0.47, \mathrm{p}<0.01)$ and positive association with life satisfaction $(r=0.29, \mathrm{p}<0.01)$. The study also explored a significant negative correlation between students' life satisfaction and their depressive symptoms $(r=-0.34, \mathrm{p}<0.01)$.

\subsection{Predictors of Psychological Adjustment (Depression)}

Multiple hierarchical regression analyses were performed to determine the predictors of depression. In running the regression analyses, predictors were inputted into the model stepwise. All control variables viz., gender, age, marital status, previous travel experience and length of stay were put in the first step of the model.

Then, while having all the step one variables in the model, self-efficacy was entered in the second step of the model. Finally, self-esteem was put into the third step of the model. Table 3 presented the regression results and indicated that the regression model concerning the combined predicting effect of demographic variables on depression was not statistically significant from zero $\left(R^{2}=\right.$

Table 2. Inter-correlations between the study variables.

\begin{tabular}{lcccccccc}
\hline \multicolumn{1}{c}{ Variables } & 1 & 2 & 3 & 4 & 5 & 6 & 7 & 8 \\
\hline 1) Gender & & & & & & & \\
2) Age & $0.29^{* *}$ & & & & & & \\
3) Marital status & $0.18^{* *}$ & $0.63^{* *}$ & & & & & \\
4) Travel experience & $-0.17^{* *}$ & 0.02 & 0.03 & & & & & \\
5) Length of stay & 0.05 & -0.03 & $-0.14^{*}$ & -0.02 & & & \\
6) Self-Efficacy & 0.04 & $0.15^{* *}$ & 0.10 & 0.05 & 0.03 & & \\
7) Self-Esteem & 0.02 & 0.01 & -0.04 & -0.03 & 0.05 & $0.43^{* *}$ & & \\
8) Life satisfaction & -0.02 & 0.04 & 0.05 & 0.01 & -0.00 & $0.43^{* *}$ & $0.29^{* *}$ & \\
9) Depression & -0.02 & -0.08 & -0.01 & -0.02 & 0.08 & $-0.29^{* *}$ & $-0.47^{* *}$ & $-0.34^{* *}$ \\
\hline
\end{tabular}

* correlation significant at the 0.05 (2-tailed); ${ }^{* *}$ correlation significant at the 0.01 (2-tailed). 
Table 3. Predicting Depression from self-efficacy and self-esteem.

\begin{tabular}{|c|c|c|c|c|c|c|c|c|}
\hline \multirow[b]{2}{*}{ Predictors } & \multirow[b]{2}{*}{ B } & \multirow[b]{2}{*}{ SEB } & \multicolumn{6}{|c|}{ Model } \\
\hline & & & Beta & $R$ & $R^{2}$ & $\Delta R^{2}$ & $\Delta F$ & $d f$ \\
\hline Step 1 & & & & 0.14 & 0.02 & & 1.24 & 5,321 \\
\hline Gender & -0.07 & 0.61 & -0.01 & & & & & \\
\hline Age & -0.12 & 0.06 & -0.14 & & & & & \\
\hline Marital Status & 1.16 & 0.89 & 0.09 & & & & & \\
\hline Travel experience & -0.17 & 0.58 & -0.02 & & & & & \\
\hline Length of stay & 0.03 & 0.02 & 0.09 & & & & & \\
\hline Step 2 & & & & 0.31 & 0.10 & 0.08 & $5.80^{* * *}$ & 6,320 \\
\hline Gender & -0.03 & 0.58 & 0.00 & & & & & \\
\hline Age & -0.09 & 0.06 & -0.10 & & & & & \\
\hline Marital Status & 1.22 & 0.85 & 0.10 & & & & & \\
\hline Travel experience & -0.02 & 0.56 & 0.00 & & & & & \\
\hline Length of stay & 0.03 & 0.02 & 0.10 & & & & & \\
\hline Self-Efficacy & -0.32 & 0.06 & $-0.29^{\star * \star}$ & & & & & \\
\hline Step 3 & & & & 0.50 & 0.25 & 0.15 & $15.32^{* * *}$ & 7,319 \\
\hline Gender & 0.00 & 0.53 & 0.00 & & & & & \\
\hline Age & -0.09 & 0.06 & -0.11 & & & & & \\
\hline Marital Status & 0.86 & 0.78 & 0.07 & & & & & \\
\hline Travel experience & -0.20 & 0.51 & -0.02 & & & & & \\
\hline Length of stay & 0.03 & 0.01 & 0.12 & & & & & \\
\hline Self-Efficacy & -0.11 & 0.06 & -0.09 & & & & & \\
\hline Self-Esteem & -0.41 & 0.05 & $-0.44^{\star * *}$ & & & & & \\
\hline
\end{tabular}

Note: Dummy variables were coded as: Gender-Male $=1$, Females $=0$; Marital status-Married $=1$, Unmarried $=0$; Prior travel experience-Yes $=1$, No $=0 .{ }^{*} \mathrm{p}<0.001$.

$\left.0.02, F_{(5,321)}=1.24, \mathrm{p}>0.05\right)$. As the present study hypothesized that self-efficacy would predict depression, the inclusion of self-efficacy in the second step significantly improved the regression model to explain $10 \%$ of the variance in depression $\left(R^{2}=0.10, F_{(6,320)}=5.80, \mathrm{p}<0.001\right)$. When the effects for the step one variables were controlled, self-efficacy contributed a significant additional $8 \%$ of the variance in the outcome variable $\left(R^{2}\right.$ change $=.08, F$ change $_{(1,320)}=28.05, \mathrm{p}$ $<0.001)$. The finding demonstrated that students' self-efficacy was negatively and significantly related to their depressive symptoms $(\beta=-0.29, \mathrm{p}<0.001)$.

The sample data also confirmed the hypothesis that self-esteem would negatively predict depression in the sense that when self-esteem was added to the third block of the model, the explanatory power of the overall model increased to explain a total of $25 \%$ of the variance in depression $\left(R^{2}=0.25, F_{(7,319)}=15.32\right.$, $\mathrm{p}<0.001)$. After controlling the effects for demographical variables and self-efficacy, self-esteem performed a significant additional $15 \%$ of the variance 
in the outcome variable $\left(R^{2}\right.$ change $=0.15, F$ change $\left._{(1,319)}=65.46, \mathrm{p}<0.001\right)$. Self-esteem was found to be negatively and significantly related to depression $(\beta$ $=-0.44, \mathrm{p}<0.001)$. Self-efficacy lost its significant predicting effect on depression upon the inclusion of the self-esteem in the third step of the regression model.

\subsection{Predictors of Psychological Adjustment (Life Satisfaction)}

A series of multiple hierarchical regression analyses were conducted to explore whether self-efficacy and self-esteem predicted depression while controlling the effects for sociodemographic variables. To perform the multiple hierarchical regression, the independent variables were entered into the regression equation in the form of steps. Step one consisted of control variables (gender, age, marital status, previous travel experience and length of stay) and self-efficacy and self-esteem were entered into the second and third steps of the model respectively. The summary of the regression results was presented in Table 4 . The step one

Table 4. Predicting Life Satisfaction from Self-efficacy and Self-esteem.

\begin{tabular}{|c|c|c|c|c|c|c|c|c|}
\hline & & & & \multicolumn{5}{|c|}{ Model } \\
\hline Predictors & B & SEB & Beta & $R$ & $R^{2}$ & $\Delta R^{2}$ & $\Delta F$ & $D f$ \\
\hline Step 1 & & & & 0.06 & 0.004 & & 0.23 & 5,321 \\
\hline Gender & -0.33 & 0.65 & -0.03 & & & & & \\
\hline Age & 0.02 & 0.07 & 0.02 & & & & & \\
\hline Marital Status & 0.57 & 0.95 & 0.04 & & & & & \\
\hline Travel experience & 0.14 & 0.63 & 0.01 & & & & & \\
\hline Length of stay & 0.00 & 0.02 & 0.01 & & & & & \\
\hline Step 2 & & & & 0.43 & 0.19 & 0.18 & $12.22^{\star * *}$ & 6,320 \\
\hline Gender & -0.39 & 0.59 & -0.04 & & & & & \\
\hline Age & -0.04 & 0.06 & -0.04 & & & & & \\
\hline Marital Status & 0.48 & 0.86 & 0.04 & & & & & \\
\hline Travel experience & -0.11 & 0.57 & -0.01 & & & & & \\
\hline Length of stay & 0.00 & 0.02 & -0.01 & & & & & \\
\hline Self-Efficacy & 0.53 & 0.06 & $0.43^{* * *}$ & & & & & \\
\hline Step 3 & & & & 0.45 & 0.20 & 0.012 & $11.31^{\star * *}$ & 7,319 \\
\hline Gender (Male) & -0.40 & 0.59 & -0.04 & & & & & \\
\hline Age & -0.03 & 0.06 & -0.04 & & & & & \\
\hline Marital Status & 0.59 & 0.86 & 0.04 & & & & & \\
\hline Travel experience & -0.05 & 0.56 & -0.01 & & & & & \\
\hline Length of stay & 0.00 & 0.02 & -0.01 & & & & & \\
\hline Self-Efficacy & 0.46 & 0.07 & 0.38 & & & & & \\
\hline Self-Esteem & 0.13 & 0.06 & $0.12^{*}$ & & & & & \\
\hline
\end{tabular}

Note: Dummy variables were coded as: Gender-Male $=1$, Females $=0$; Marital status-Married $=1$, Unmarried $=0$; Prior travel experience-Yes $=1$, No $=0 .{ }^{*} \mathrm{p}<0.001$. 
finding delineated that the controlling variables performed a very small percent of variance $(0.4 \%)$ in depression and the regression model was not statistically different from zero $\left(R^{2}=0.004, F_{(5,321)}=0.23, \mathrm{p}>0.05\right)$.

However, when self-efficacy was incorporated in the second step, the overall model appeared to be statistically significant from zero $\left(R^{2}=0.19, F_{(6,320)}=12.22\right.$, $\mathrm{p}<0.001)$ and accounted for by $19 \%$ of the variance in the criterion variable. As expected, when the effects for control variables were controlled, self-efficacy contributed additional $18 \%$ variance in life satisfaction and was statistically significant $\left(R^{2}\right.$ change $=0.18, F$ change $\left.{ }_{(1,320)}=71.89, \mathrm{p}<0.001\right)$. The standardized regression coefficient depicted that there was a significant positive relationship between self-efficacy and satisfaction with life $(\beta=0.43, \mathrm{p}<0.001)$. Finally, when self-esteem was included in the third step of the model, all the predictors jointly explained $20 \%$ of the variance in the regressed variable and the model was significantly different from zero $\left(R^{2}=0.20, F_{(7,319)}=11.31, \mathrm{p}<0.001\right)$.

It was also hypothesized that self-esteem would predict life satisfaction and when the effects for control variables and self-efficacy were excluded, self-esteem appeared to have a small proportion of variance $(1.2 \%)$ in the outcome albeit the model was significant at 0.05 alpha level $\left(R^{2}\right.$ change $=0.012, F$ change $_{(1,319)}=4.97, \mathrm{p}$ $<0.05)$. The standardized regression coefficient showed that self-esteem was positively related to satisfaction with life $(\beta=0.12, \mathrm{p}<0.001)$. Interestingly, when self-esteem was included in the third step of the model, self-efficacy failed to maintain its significant predicting effect on satisfaction with life $(\beta=0.07, \mathrm{p}>$ 0.05).

\subsection{Mediation Analyses}

\section{The Mediating Effects of Self-Esteem and Life Satisfaction}

A regression analysis using PROCESS macro was conducted to further determine the parallel mediating effects of self-esteem and life satisfaction on the relationship between self-efficacy and psychological adjustment variable of depression. According to Baron and Kenny [67], mediation takes place when the following four conditions are satisfied. First, the mediator must significantly regress on the independent variable. Second, the dependent variable must significantly regress on the mediator. Third, the dependent variable must significantly regress on the independent variable. Fourth, the regression of the dependent variable on the independent variable must weaken (partial mediation) or must be non-significant (full mediation) when the mediators are controlled

The regression results for the present sample data (see Figure 1) fulfilled the four condition of Baron and Kenny in the way that the intermediary variables of self-esteem and satisfaction with life significantly regressed on self-efficacy $(b=$ $0.52, t=8.54, \mathrm{p}<0.001 ; \mathrm{b}=0.52, t=8.52, \mathrm{p}<0.001)$. Self-esteem and life satisfaction significantly predicted depression $(\mathrm{b}=-0.38, t=-7.53, \mathrm{p}<0.001 ; \mathrm{b}=$ $-0.20, t=-4.06, \mathrm{p}<0.001)$ and self-efficacy was also a significant predictor of depression when the effects for the mediators were not controlled $(\mathrm{b}=-0.33, t=$ $-5.42, \mathrm{p}<0.001)$. However, when the mediating effects were removed, 


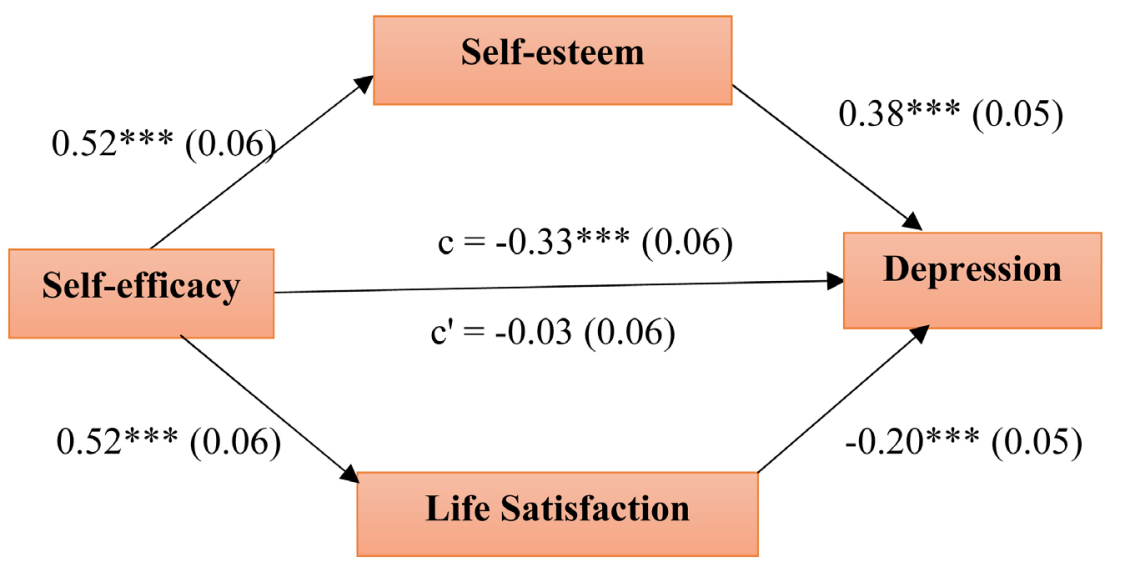

Figure 1. Presented the unstandardized coefficients for the regression paths in the model with standard errors in parentheses. ${ }^{* *} \mathrm{p}<0.001$.

self-efficacy no longer maintained its significant effect on depression $(b=-0.03$, $t=-0.44, \mathrm{p}=0.657$ ), indicating that self-esteem and life satisfaction fully mediated the relationship between self-efficacy and depression. Bootstrapping estimation method with 5000 samples [68] was applied to test the significance of indirect effects. The result showed significant indirect effects of both the mediating variables of self-esteem $(\mathrm{b}=-0.19, \mathrm{SE}=0.04,95 \% C I=-0.28$ to -0.12$)$ and life satisfaction $(\mathrm{b}=-0.10, \mathrm{SE}=0.03,95 \% C I=-0.17$ to -0.05$)$ and the merged indirect effect was $(\mathrm{b}=-0.30, \mathrm{SE}=0.05,95 \% C I=-0.40$ to -0.20$)$.

Similarly, the sample data fulfilled the conditions for the mediating effect of self-esteem on the relationship between self-efficacy and life satisfaction (see Figure 2). The unstandardized regression coefficients showed that all the direct paths between the predictor, mediator and criterion variable were significant. More explicitly, self-efficacy performed a significant negative predicting effect on self-esteem ( $\mathrm{b}=0.52, t=8.54, \mathrm{p}<0.001)$. Self-esteem was also found to be positively related to life satisfaction $(\mathrm{b}=0.13, t=2.33, \mathrm{p}<0.001)$. Besides, life satisfaction significantly regressed on self-efficacy $(\mathrm{b}=0.52, t=8.52, \mathrm{p}<0.001)$. When the intervening effect of self-esteem was removed, the effect of self-efficacy on life satisfaction was decreased but continued to remain significant $(\mathrm{b}=0.45, t$ $=6.75, \mathrm{p}<0.001)$ which marked the partial positive mediating effect of the self-esteem. Bootstrapping estimation method with 5000 samples [68] was applied to test the significance of the indirect effect. The result showed that the indirect effect was evident since the interval did not contain zero $(\mathrm{b}=-0.07, \mathrm{SE}=$ $0.03,95 \% C I=0.01$ to 0.14 ).

\section{Discussion}

The study attempted to uncover the relationships between self-efficacy, self-esteem and psychological adjustment. It further endeavored to discover the mediating effects of self-esteem and life satisfaction. The results revealed that both self-efficacy and self-esteem positively related to depression and inversely related to life satisfaction. The parallel intervening effects of self-esteem and life satisfaction were 


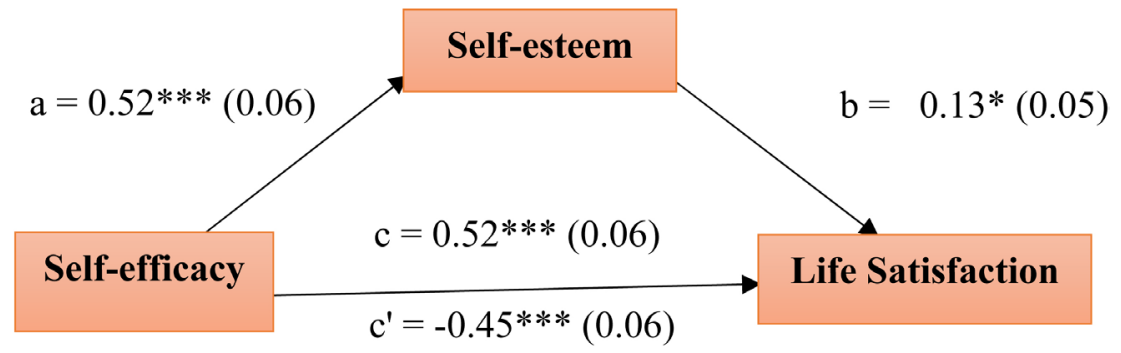

Figure 2. Illustrated the unstandardized coefficients for the regression paths (paths $a, b$ and c) between the variables with standard errors in parentheses. ${ }^{\star} \mathrm{p}<0.05,{ }^{* *} \mathrm{p}<0.001$.

also evident. Similarly, self-esteem mediated the relationship between self-efficacy and satisfaction with life.

Following the psychological stress and coping paradigm, the study first hypothesized that self-efficacy would relate to psychological adjustment. Findings from regression analyses supported the hypothesis where students with higher self-efficacy were found to have better psychological adaptation (i.e., fewer depressive symptoms and higher life satisfaction). Numerous cross-cultural scholars have argued that personal coping resources are essential features of acculturative outcomes of sojourners in the new environment [9] [25]. In this sense, students who make the best use of their strong beliefs on their capability or copings to effectively deal with acculturation difficulties achieve better adaptation in host environment because beliefs of personal coping resources are central to achievements. On the other hand, when individuals believe that they are not capable of handling the inherently stressful acculturative encounters successfully, they cannot succeed in the making [31]. Similarly, Li and Gasser [33] suggested that students with high self-efficacy have good cognitive imagery to visualize the desirable psychological adjustment outcome which stimulates them to mobilize their full individual resources in dealing with intercultural problems. Several empirical cross-cultural studies have also echoed that students' self-efficacy is negatively associated with mental health problems such as stress and depression and positively associated with life satisfaction and psychological well-being, suggesting that the higher the level of self-efficacy, the better the psychological adjustment outcome [34] [35] [36] [37] [38].

The finding of the present sample data also corroborated the second hypothesis that self-esteem significantly predicted psychological adjustment, representing that students with positive self-evaluation reported better satisfaction with their life and low depression. The finding corresponds the notion that individuals' positive self-regard as a personal resource creates a sense of motivation and positive attitude in the arena of psychological acculturation and thereby enhances their sense of self-esteem [41] [42]. Thus, international students with higher self-esteem continue to make a persistent effort to effectively function in the intercultural transition in order to maintain their worthiness. Although there is a paucity of cross-cultural studies on self-esteem, a few studies suggest that individuals' self-esteem is negatively related to their feeling of loneliness and depression [50] 
[51] and positively related to their life satisfaction [52].

Interestingly, the findings of the study provided evidence to confirm the third hypothesis that self-esteem and satisfaction with life performed full parallel mediational effects on the relationship between self-efficacy and depression, meaning that students' self-efficacy directly enhanced their self-esteem and life satisfaction and thereby indirectly reduced their depressive symptoms. In line with our finding, previous studies have also documented that self-esteem mediated the relationship of self-efficacy with depression [55]. Despite the studies on the mediating role of life satisfaction are significantly limited, from the present sample data, it can be inferred that students' beliefs in their capacity to successfully adjust to the new environment may provide a favorable ground for their positive attitude, perception, and sense of satisfaction with their life. Subsequently, with an increase in students' sense of satisfaction, mental health problems such as depression might be diminished. In contrary, students' feeling of dissatisfaction rooted in poor adjustment due to low self-efficacy might intensify the level of depression. In line with our inference, several scholars believe that sense of life satisfaction is closely associated with their accomplishments [31] [69] and the people are happy, hopeful about the future and give less attention to negative events [70].

The study further supported the fourth expectation that self-esteem intervened the relationship between self-efficacy and satisfaction with life, showing students with a high level of self-efficacy showed a positive self-evaluation and subsequently were found to be satisfied with their life. The finding can be explained in the sense that students with high self-efficacy remain to be confident to deal with psychological adjustment difficulties effectively and this helps them to uphold positive self-evaluation and proud of their triumphs which consequently proliferate their general satisfaction with life. Although studies on this issue are insufficient, some studies, parallel to our finding, reported that self-esteem played an intermediating role on self-efficacy and life satisfaction [56].

The study had some shortcomings which need to be considered in future research endeavors. First, the study's sample was limited to international students studying in three universities situated in Wuhan. Therefore, the findings of the study might not have good external validity. Given this, future studies might duplicate the study using large and representative samples to confirm and extend the present findings. Second, the study was a survey study relied on the self-administered questionnaire in which respondents' lack of honesty and social desirability might affect the accuracy of the findings. To get relief from such drawbacks, future studies may plan to adopt experimental or mixed research approaches. Third, since the study was a cross-sectional study, variables were measured within one point in time albeit measuring the students' psychological adjustment at a different point in time using a longitudinal study might better explain the phenomena. Fourth, the study was also a descriptive study limited to determine the relationship between the study variables without establishing causality and controlling the potential confounding effect of extraneous variables. 


\section{Conclusion}

Among the many factors, individual difference variables are believed to be critical aspects of students' psychological adjustment. The present study was conducted in this general context to determine the relationship between self-efficacy, self-esteem and psychological adjustment variables of depression and life satisfaction. The study discovered that both students' self-efficacy and self-esteem play a vital role in coping with adverse psychological acculturative outcomes such as depression and boosting the sense of general life satisfaction. More importantly, the indirect effects of self-efficacy on depression through self-esteem and life satisfaction were evident. Similarly, self-esteem intervened the relationship between self-efficacy and life satisfaction. Findings of the study highlight that psychological factors of self-esteem and self-efficacy are necessary features of the successful psychological intercultural transition of international students.

\section{Implications}

The study's effort to discover the relationship between self-efficacy, self-esteem and psychological adjustment is believed to contribute to the cross-cultural literature. Notably, the mediating effects of self-efficacy and life satisfaction might remind cross-cultural researchers that the process of psychological acculturation is quite complicated involving the impacts of various intertwined psychological factors. Besides, the findings of the study might have practical implications for the higher education institutions to serve their international students better and safeguard them from overwhelming mental health outcomes. University communities can work on aiding the students to have a belief in their capacity to succeed and have a positive evaluation of themselves. Also, mental health personnel might benefit from the present findings to first channel their counseling services toward students who fail to cope with adjustment difficulties and experience feelings of depression and dissatisfaction in the new environment rooted in their low self-efficacy and self-esteem. On top of these points, findings may help lecturers of international students to create an engaging learning environment that enables students to maintain a certain level of accomplishment and thereby augments their level of self-esteem and joy of learning in the host environment.

\section{Conflicts of Interest}

The authors declare no conflicts of interest regarding the publication of this paper.

\section{References}

[1] Jibeen, T. and Khan, M.A. (2015) Internationalization of Higher Education: Potential Benefits and Costs. International Journal of Evaluation and Research in Education, 4, 196-199.

[2] Yu, B. and Wright, E. (2016) Socio-Cultural Adaptation, Academic Adaptation and 
Satisfaction of International Higher Degree Research Students in Australia. Tertiary Education and Management, 22, 49-64. https://doi.org/10.1080/13583883.2015.1127405

[3] Altbach, P.G. and Knight, J. (2007) The Internationalization of Higher Education: Motivations and Realities. Journal of Studies in International Education, 11, 290-305. https://doi.org/10.1177/1028315307303542

[4] Mustaffa, C.S. and Ilias, M. (2013) Relationship between Students Adjustment Factors and Cross Cultural Adjustment: A Survey at the Northern University of Malaysia. Intercultural Communication Studies, 1, 279-300.

[5] Sumra, K.B. (2012) Study on Adjustment Problems of International Students Studying in Universities of The People's Republic of China: A Comparison of Student and Faculty/Staff Perceptions. International Journal of Education, 4, 107-126. https://doi.org/10.5296/ije.v4i2.1181

[6] Wen, W., Hu, D. and Hao, J. (2017) International Students' Experiences in China: Does the Planned Reverse Mobility Work? International Journal of Educational Development, 61, 204-212. https://doi.org/10.1016/j.ijedudev.2017.03.004

[7] Ministry of Education of the Republic of China (2018) Growing Number of Foreign Students Choosing to Study in China for a Degree across Multiple Disciplines. http://en.moe.gov.cn/News/Top_News/201804/t20180403_332258.html

[8] Bista, K. (2019) Exploring the Field: Understanding the International Student Experience. In: Bista, K., Ed., Global Perspectives on International Student Experiences in Higher, Routledge, New York, 1-16.

[9] Berry, J.W. (2005) Acculturation: Living Successfully in Two Cultures. International Journal of Intercultural Relations, 29, 697-712. https://doi.org/10.1016/j.ijintrel.2005.07.013

[10] Berry, J.W., Kim, U., Minde, T. and Mok, D. (1987) Comparative Studies of Acculturative Stress. The International Migration Review, 21, 491-511. https://doi.org/10.2307/2546607

[11] Mori, S.C. (2000) Addressing the Mental Health Concerns of International Students. Journal of Counseling and Development, 78, 137-143. https://doi.org/10.1002/j.1556-6676.2000.tb02569.x

[12] Ye, H.D. and Juni, M.H. (2018) Predictors of Acculturative Stress among International Postgraduate Students in Malaysia Public University. International Journal of Public Health and Clinical Sciences, 5, 155-172. http://publichealthmy.org/ejournal/ojs2/index.php/ijphcs/article/view/647/477

[13] Mesidor, J.K. and Sly, K.F. (2016) Factors that Contribute to the Adjustment of International Students. Journal of International Students, 6, 262-282.

[14] Sandhu, D.S. (1994) An Examination of the Psychological Needs of the International Students: Implications for Counselling and Psythotherapy. International Journal for the Advancement of Counselling, 17, 229-239. https://doi.org/10.1007/BF01407739

[15] Yu, B., Chen, X., Li, S., Liu, Y., Jacques-Tiura, A.J. and Yan, H. (2014) Acculturative Stress and Influential Factors among International Students in China: A Structural Dynamic Perspective. PLoS ONE, 9, e96322. https://doi.org/10.1371/journal.pone.0096322

[16] Liu, Y., Chen, X., Li, S., Yu, B., Wang, Y. and Yan, H. (2016) Path Analysis of Acculturative Stress Components and Their Relationship with Depression among International Students in China. Stress and Health, 32, 524-532. https://doi.org/10.1002/smi.2658 
[17] Gebregergis, W.T. (2018) Major Causes of Acculturative Stress and Their Relations with Sociodemographic Factors and Depression among International Students. Open Journal of Social Sciences, 6, 68-87. https://doi.org/10.4236/jss.2018.610007

[18] Wilson, J.K. (2013) Exploring the Past, Present, and Future of Cultural Competency Research: The Revision and Expansion of the Sociocultural Adaptation Construct. Unpublished Doctoral Dissertation, Victoria University of Wellingon, Wellington.

[19] Searle, W. and Ward, C. (1990) The Prediction of Psychological and Sociocultural Adjustment during Cross-Cultural Transitions. International Journal of Intercultural Relations, 14, 449-464. https://doi.org/10.1016/0147-1767(90)90030-Z

[20] Ward, C. and Kennedy, A. (1994) Acculturation Strategies, Psychological Adjustment, and Sociocultural Competence during Cross-Cultural Transitions. International Journal of Intercultural Relations, 18, 329-343. https://doi.org/10.1016/0147-1767(94)90036-1

[21] Sam, D.L. and Berry, J.W. (2010) Acculturation: When Individuals and Groups of Different Cultural Backgrounds Meet. Perspectives on Psychological Science, 5, 472-481. https://doi.org/10.1177/1745691610373075

[22] Ward, C., Bochner, S. and Furnham, A. (2005) The Psychology of Culture Shock. Routledge, London. https://doi.org/10.4324/9780203992258

[23] Lazarus, R.S. and Folkman, S. (1984) Stress, Appraisal, and Coping. Springer Publishing Company, New York.

[24] Berry, J.W. (2006) Acculturative Stress. In: Wong, P.T.P. and Wong, L.C.J., Eds., Handbook of Multicultural Perspectives on Stress and Coping, Springer, Boston, 287-298. https://doi.org/10.1007/0-387-26238-5_12

[25] Rudmin, F. (2009) Constructs, Measurements and Models of Acculturation and Acculturative Stress. International Journal of Intercultural Relations, 33, 106-123. https://doi.org/10.1016/j.ijintrel.2008.12.001

[26] Harrison, J.K. and Brower, H.H. (2011) The Impact of Cultural Intelligence and Psychological Hardiness on Homesickness among Study Abroad Students. The Interdisciplinary Journal of Study Abroad, 21, 31-62. https://files.eric.ed.gov/fulltext/EJ991042.pdf

[27] Ayoob, M. and Alsultan, A. (2017) Cultural Intelligence as a Moderator of Acculturative Stress to Health among College Students. International Journal of Science and Research, 6, 1905-1910.

[28] Hechanova-Alampay, R., Beehr, T.A., Christiansen, N.D. and Van Horn, R.K. (2002) Adjustment and Strain among Domestic and International Student Sojourners: A Longitudinal Study. School Psychology International, 23, 458-474. https://doi.org/10.1177/0143034302234007

[29] Bandura, A. (1989) Human Agency in Social Cognitive Theory. American Psychologist, 44, 1175-1184. https://doi.org/10.1037/0003-066X.44.9.1175

[30] Bandura, A. (1990) Some Reflections on Reflections. Psychological Inquiry, 1, 101-105. https://doi.org/10.1207/s15327965pli0101_26

[31] Bandura, A. (1997) Self-Efficacy: The Exercise of Control. W.H. Freeman and Company, New York.

[32] Harrison, J.K., Chadwick, M. and Scales, M. (1996) The Relationship between Cross-Cultural Adjustment and the Personality Variables of Self-Efficacy and Self-Monitoring. International Journal of Intercultural Relations, 20, 167-188. https://doi.org/10.1016/0147-1767(95)00039-9

[33] Li, A. and Gasser, M.B. (2005) Predicting Asian International Students' Sociocul- 
tural Adjustment: A Test of Two Mediation Models. International Journal of Intercultural Relations, 29, 561-576. https://doi.org/10.1016/j.ijintrel.2005.06.003

[34] Bulgan, G. and Çiftçi, A. (2017) Psychological Adaptation, Marital Satisfaction, and Academic Self-Efficacy of International Students. Journal of International Students, 7, 687-702.

[35] Yusoff, Y.M. (2011) Self-Efficacy, Perceived Social Support, and Psychological Adjustment in International Undergraduate Students in a Public Higher Education Institution in Malaysia. Journal of Studies in International Education, 16, 353-371. https://doi.org/10.1177/1028315311408914

[36] Poyrazli, S., Arbona, C., Nora, A., McPherson, R. and Pisecco, S. (2002) Relation between Assertiveness, Academic Self-Efficacy, and Psychosocial Adjustment among International Graduate Students. Journal of College Student Development, 43, 632-642.

[37] Moeini, B., Shafii, F., Hidarnia, A., Babaii, G.R., Birashk, B. and Allahverdipour, H. (2008) Perceived Stress, Self-Efficacy and Its Relations to Psychological Well-Being Status in Iranian Male High School Students. Social Behavior and Personality. An International Journal, 36, 257-266. https://doi.org/10.2224/sbp.2008.36.2.257

[38] Riaz Ahmad, Z., Yasien, S. and Ahmad, R. (2014) Relationship between Perceived Social Self-Efficacy and Depression in Adolescents. Iranian Journal of Psychiatry and Behavioral Sciences, 8, 65-74.

[39] Constantine, M.G., Okazaki, S. and Utsey, S.O. (2004) Self-Concealment, Social Self-Efficacy, Acculturative Stress, and Depression in African, Asian, and Latin American International College Students. American Journal of Orthopsychiatry, 74, 230-241. https://doi.org/10.1037/0002-9432.74.3.230

[40] Bosson, J. and Swann, W.B. (2009) Self-Esteem: Nature, Origins, and Consequences. In: Leary, R.H.M., Ed., Handbook of Individual Differences in Social Behavior, Guilford, New York, 527-546.

[41] Gholamrezaei, A. (1995) Acculturation and Self-Esteem as Predictors of Acculturative Stress among International Students at the University of Wollongong. Doctoral Dissertation, Department of Public Health and Nutrition, University of Wollongong, Wollongong.

[42] Kernis, M.H. (2003) Toward a Conceptualization of Optimal Self-Esteem. Psychological Inquiry, 14, 1-26. https://doi.org/10.1207/S15327965PLI1401_01

[43] Park, L.E. and Crocker, J. (2013) Pursuing Self-Esteem: Implication for self-Regulation and Relationships. In: Zeigler-Hill, V., Ed., Self-Esteem, Psychology Press, Brighton and Hove, East Sussex, 43-59.

[44] Zeigler-Hill, V. (2013) The Importance of Self-Esteem. In: Zeigler-Hill, V., Ed., Self-Esteem, Psychology Press, Brighton and Hove, East Sussex, 1-20. https://doi.org/10.4324/9780203587874

[45] Anderson, L.P. (1991) Acculturative Stress: A Theory of Relevance to Black Americans. Clinical Psychology Review, 11, 685-702. https://doi.org/10.1016/0272-7358(91)90126-F

[46] Billings, A.C. and Moos, R.H. (1982) Psychosocial Theory and Research on Depression: An Integrative Framework and Review. Clinical Psychology Review, 2, 213-237. https://doi.org/10.1016/0272-7358(82)90013-7

[47] Sternberg, R.J. and Vroom, V. (2002) The Person versus the Situation in Leadership. The Leadership Quarterly, 13, 301-323. https://doi.org/10.1016/S1048-9843(02)00101-7 
[48] Dong, Q., Koper, R.J. and Collaço, C.M. (2008) Social Intelligence, Self-Esteem, and Intercultural Communication Sensitivity. Intercultural Communication Studies, 17, 162-172.

[49] Kim, E., Hogge, I. and Salvisberg, C. (2014) Effects of Self-Esteem and Ethnic Identity: Acculturative Stress and Psychological Well-Being among Mexican Immigrants. Hispanic Journal of Behavioral Sciences, 36, 144-163. https://doi.org/10.1177/0739986314527733

[50] Cheng, H. and Furnham, A. (2003) Personality, Self-Esteem, and Demographic Predictions of Happiness and Depression. Personality and Individual Differences, 34, 921-942. https://doi.org/10.1016/S0191-8869(02)00078-8

[51] Smith, H.M. and Betz, N.E. (2002) An Examination of Efficacy and Esteem Pathways to Depression in Young Adulthood. Journal of Counseling Psychology, 49, 438-448. https://doi.org/10.1037/0022-0167.49.4.438

[52] Bozorgpour, F. and Salimi, A. (2012) State Self-Esteem, Loneliness and Life Satisfaction. Procedia-Social and Behavioral Sciences, 69, 2004-2008. https://doi.org/10.1016/j.sbspro.2012.12.157

[53] Lane, J., Lane, A.M. and Kyprianou, A. (2004) Self-Efficacy, Self-Esteem and Their Impact on Academic Performance. Social Behavior and Personality. An International Journal, 32, 247-256. https://doi.org/10.2224/sbp.2004.32.3.247

[54] Hajloo, N. (2014) Relationships between Self-Efficacy, Self-Esteem and Procrastination in Undergraduate Psychology Students. Iranian Journal of Psychiatry and Behavioral Sciences, 8, 42-49.

[55] Hermann, K.S. (2005) The Influence of Social Self-Efficacy, Self-Esteem, and Personality Differences on Loneliness and Depression. Doctoral Dissertation, Ohio State University, Columbus.

[56] Liu, Y., Wang, Z., Zhou, C. and Li, T. (2014) Affect and Self-Esteem as Mediators between Trait Resilience and Psychological Adjustment. Personality and Individual Differences, 66, 92-97. https://doi.org/10.1016/j.paid.2014.03.023

[57] Capri, B., Ozkendir, O.M., Ozkurt, B. and Karakus, F. (2012) General Self-Efficacy Beliefs, Life Satisfaction and Burnout of University Students. Procedia-Social and Behavioral Sciences, 47, 968-973. https://doi.org/10.1016/j.sbspro.2012.06.765

[58] Chang, A.-K., Park, J. and Sok, S.R. (2013) Relationships among Self-Efficacy, Depression, Life Satisfaction, and Adaptation among Older Korean Adults Residing in For-Profit Professional Nursing Facilities. The Journal of Nursing Research, 21, 162-169. https://doi.org/10.1097/01.jnr.0000432047.93802.df

[59] Zhang, J. and Goodson, P. (2011) Acculturation and Psychosocial Adjustment of Chinese International Students: Examining Mediation and Moderation Effects. International Journal of Intercultural Relations, 35, 614-627. https://doi.org/10.1016/j.ijintrel.2010.11.004

[60] Schwarzer, R. and Jerusalem, M. (1995) Generalized Self-Efficacy Scale. In: Weinman, S.W.J. and Johnston, M., Eds., Measures in Health Psychology: A User's Portfolio, Causal and Control Beliefs, NFER-NELSON, Windsor, 35-37.

[61] Rosenberg, M. (1965) Society and the Adolescent Self-Image. Princeton University, Princeton. https://doi.org/10.1515/9781400876136

[62] Mohebbi, M., Nguyen, V., McNeil, J.J., Woods, R.L., Nelson, M.R., Shah, R.C. and Berk, M. (2018) Psychometric Properties of a Short Form of the Center for Epidemiologic Studies Depression (CES-D-10) Scale for Screening Depressive Symptoms in Healthy Community Dwelling Older Adults. General Hospital Psychiatry, 51, 
118-125. https://doi.org/10.1016/j.genhosppsych.2017.08.002

[63] Diener, E., Emmons, R.A., Larsen, R.J. and Griffin, S. (1985) The Satisfaction with Life Scale. Journal of Personality Assessment, 49, 71-75. https://doi.org/10.1207/s15327752jpa4901_13

[64] Pavot, W. and Diener, E. (2008) The Satisfaction with Life Scale and the Emerging Construct of Life Satisfaction. The Journal of Positive Psychology, 3, 137-152. https://doi.org/10.1080/17439760701756946

[65] George, D. and Mallery, P. (2003) SPSS for Windows Step by Step: A Simple Guide and Reference. 11.0 Update, 4th Edition, Allyn \& Bacon, Boston.

[66] Gravetter, F. and Wallnau, L. (2014) Essentials of Statistics for the Behavioral Sciences. 8th Edition, Wadsworth, Belmont.

[67] Baron, R.M. and Kenny, D. (1986) The Moderator-Mediator Variable Distinction in Social Psychological Research: Conceptual, Strategic, and Statistical Considerations. Journal of Personality and Social Psychology, 51, 1173-1182. https://doi.org/10.1037/0022-3514.51.6.1173

[68] Preacher, K.J. and Hayes, A.F. (2004) SPSS and SAS Procedures for Estimating Indirect Effects in Simple Mediation Models. Behavior Research Methods, Instruments and Computers, 36, 717-731. https://doi.org/10.3758/BF03206553

[69] Ansari, M. and Khan, S.A. (2015) Self-Efficacy as a Predictor of Life Satisfaction among Undergraduate Students. The International Journal of Indian Psychology, 2, 5-11.

[70] Seligman, M. (2002) Positive Emotions Undo Negative Ones. Authentic Happiness. Simon \& Schuster, New York. 